\title{
Comparative Study of Ephedrine and Mephertermine in Treatment of Hypotension in Patients Undergoing Elective Trans Urethral Resection Prostate (TURP)
}

\author{
N PURI ${ }^{\mathrm{a}}$, A TALWAR ${ }^{\mathrm{b}}$
}

\begin{abstract}
Summary:
The present study was carried out on forty ASA I and II patients undergoing elective trans urethral resection of bladder tumour and ICA implant for carcinoma cervix under subarachnoid block. The patients were randomly divided into two groups each consisting of 20 patients. Vasopressors were used when the systolic blood pressure decreased by $25 \%$ pressure of the baseline or less than 90 mm Hg after subarachnoid block.Group I received
\end{abstract}

\section{Introduction}

Hypotension after spinal anaesthesia can be so severe that without prevention or treatment it can go beyond the limit of physiologic trespass, leading to complications like nausea, bradycardia, vomiting, arrhythmias or even cardiac arrest ${ }^{1}$. The incidence of hypotension during subarachnoid block in elderly patients ranges from $25-69 \% .{ }^{4}$ The elderly are at an increased risk of developing long term complications from hypotension because they have a reduced physiologic reserve and an increased incidence of systemic disease. In adults and obstetric patients, the management of hypotension after subarachnoid block is well established but it is not so in elderly patients. The preloading used to correct hypotension in the elderly has not always been shown to be effective. In addition, in elderly patients preloading with large fluid volumes may be poorly tolerated resulting in fluid overload of the various vasopressors available, ephedrine is found to be the most effective in the treatment of hypotension. It is speculated that ephedrine is incapable of correlating the decrease in

a. Dr Neerja Puri, Registrar Anaesthesia

b. Dr Ashutsoh Talwar, Assistant Professor Surgery

Department of Anaesthesia \& Surgery, G.G.S. Medical College \& Hospital, Faridkot. 151203. Punjab.

Address of Correspondence: Dr Neerja Puri, \# 626, Phase II, Urban Estate, Dugri Road, Ludhiana, Punjab. India, Email : neerjaashu @)rediffmail.com, Cell : 09814616427

Received: 16 July, 2008

Accepted: 7 September, 2009 injection Ephedrine $10 \mathrm{mg}$ bolus and immediately an infusion was started at the rate of $30 \mathrm{mg} / \mathrm{hr}$. group II patients received injection Mephentermine intravenous 10 $\mathrm{mg}$ followed by an infusion of $60 \mathrm{mg} / \mathrm{hr}$. The clinical parameters observed during the procedure were measurement of heart rate, systolic/diastolic and mean blood pressure and CVP. The two groups were statistically compared with respect to the above parameters.

(J Bangladesh Coll Phys Surg 2010; 28: 10-16)

systemic vascular resistance and since the elderly have a reduced physiological reserve they are less capable of increasing their cardiac output in response to ephedrine ${ }^{2,3}$. In addition, it causes a large increase in heart rate which is detrimental in elderly individuals ${ }^{4}$. An alpha agonist like metarminol is thought to act by increasing both systemic vascular resistance and CVP. It is capable of maintaining the systemic pressure by venoconstriction actions. Similarly, mephentermine has also got sympathomimatic action. It causes a rise in blood pressure due to a combination of ionotropic and vasoconstrictor actions. Similarly, mephentermine has also got sympathomimetic action. It causes a rise in B.P. due to a combination of ionotropic and vasoconstrictor actions. Moreover, it is the most freely available vasopressors in our set up.

\section{Material \& Methods}

It was randomized conducted on 40 ASA I and II patients of more than 60 years undergoing urologic/ surgical procedure for approximately 1 hour under subarachnoid block. All the patients were clinically examined for any other medical illness and investigated preoperatively. The purpose of the study, details regarding regional anaesthesia was explained to the patients and informed consent for the procedure was obtained. The patients were randomly divided into two groups.

Group I Received injection ephedrine $10 \mathrm{mg}$ bolus intravenously ( $0.2 \mathrm{mg} / \mathrm{kg}$ ) followed by infusion 0.6 $\mathrm{mg} / \mathrm{kg} / \mathrm{hr}(30 \mathrm{mg} / \mathrm{hr})$. 
Group II Received injection mephentermine $10 \mathrm{mg}$ bolus followed by $1 \mathrm{mg} / \mathrm{min}$ or $60 \mathrm{mg} / \mathrm{hr}$ infusion.

\section{Exclusion Criteria}

The following patients were excluded from our study:

1. Patients with severe cardiac or respiratory diseases like ILD and uncontrolled diabetes mellitus.

2. Patients with abnormal cardiac anatomy like valvular heart disease, dilated cardiomyopathy.

3. Patients with heart rhythm other than sinus rhythm.

4. Patients receiving medication which have direct cardiac effect eg Beta blockers, vasodilators, antihypertensives.

5. Patients with haemoglobin less than 10 gram $\%$.

6. Patients having contraindication to subarachnoid block.

All patients were fasting since twelve midnight before the day of surgery. For Premedication they received tablet Daizepam $5 \mathrm{mg}$ at bedtime and $5 \mathrm{mg}$ on the morning of surgery. On the operating table a cental venous pressure monitoring catheter was passed through antecubital vein under local anaesthesia, taking all aseptic precautions. Before giving the block HR, BP (Systolic, diastolic and mean) and CVP were measured and they were taken as preblock values.

Subarachnoid block was given in the lateral position at $\mathrm{L}_{2-3}$ or $\mathrm{L}_{3-4}$ space with a $25 \mathrm{G}$ spinal needle using $2.5 \mathrm{ml}$ of $0.5 \%$ heavy bupivacaine. Soon after giving the drug in suarachnoid space patients position was changed from lateral to supine and patients stayed in the position till the end of surgery. Fluids were administered as $4 \mathrm{ml} / \mathrm{kg} / \mathrm{hr}$ of normal saline.the vasopressors were administered when systolic arterial pressure dropped to more than $25 \%$ of the baseline or less than $90 \mathrm{~mm} \mathrm{Hg}$ systolic blood pressure. The vasopressors were given first as intravenous bolus and then immediately an infusion of either ephedrine or mephenteramine was started. The various parameters which were monitored during the procedure were :

- ECG lead II for HR and rhythm.
- NIBP every 2 min for first 15 min and then every $5 \mathrm{~min}$ for $30 \mathrm{~min}$.

- CVP every $15 \mathrm{~min}$.

- Level of block was determined by pin prick method every $2 \mathrm{~min}$ upto $15 \mathrm{~min}$.

\section{Results:}

Table-I

Patient Characteristics (Mean + SD)

\begin{tabular}{lcc} 
& Group I $(\mathrm{n}=20)$ & Group II $(\mathrm{n}=20)$ \\
\hline Age $(\mathrm{yrs})$ & $66.55+3.20$ & $65.95+2.28$ \\
Sex $(\mathrm{M} / \mathrm{F})$ & $14 / 6$ & $15 / 5$ \\
\hline
\end{tabular}

$\mathrm{p}>0.05$

\section{Table-2}

Technical variables of subarachnoid block (number of patients - Percentage)

The parameters were comparable for both the groups.

\begin{tabular}{ccc}
\hline SAB AT L2- L3 & $8(40 \%)$ & $8(40 \%)$ \\
SAB AT L3 L4 & $12(60 \%)$ & $12(60 \%)$ \\
Level of block at 14 min. & & \\
T7 & 0 & $1(5 \%)$ \\
T8 & $17(85 \%)$ & $15(75 \%)$ \\
T9 & $3(15 \%)$ & $4(20 \%)$
\end{tabular}

$\mathrm{p}>0.05$

$\mathrm{SAB}$ performed at $\mathrm{L}_{2,3}$ in 8 patients and $\mathrm{L}_{3,4}$ in 12 patients.

\section{Table-III}

Pre Block Haemodynamic variables (Mean $+S D)$

These were comparable in both the groups.

Group I $(\mathrm{n}=20) \quad$ Group II $(\mathrm{n}=20)$

Heart rate $(\mathrm{bpm}) \quad 77.40+6.44 \quad 78.10+3.86$

Blood pressure

(Mephentermine $\mathrm{Hg}$ )

Systolic

Diastolic $\quad 123.55+8.98 \quad 124.20+7.98$

Mean $\quad 78.40+6.03 \quad 79.60+6.54$

\begin{tabular}{lrl}
$93.70+5.71$ & $94.50+6.69$ \\
\hline CVP (cms of n.s.) & $8.55+0.88$ & $8.30+0.92$
\end{tabular}

$\mathrm{p}>0.05$ 


\section{Table-IV}

Changes in heart rate (HR) from preblock values and rate of changes between two groups (Mean $+S D)$

\begin{tabular}{|c|c|c|c|c|}
\hline Time (min) & HR (bpm) & Changesin HR & $\mathrm{p}$ value & Group I vs II \\
\hline \multicolumn{5}{|l|}{00} \\
\hline Group I & \pm 6.44 & & & \\
\hline Group II & $78.10+3.86$ & & & \\
\hline \multicolumn{5}{|l|}{02} \\
\hline Group I & $77.40 \pm 6.44$ & $0.00 \pm 0.00$ & $>0.05$ & $>0.05$ \\
\hline Group II & $78.10 \pm 3.86$ & $0.00 \pm 0.92$ & $>0.05$ & \\
\hline \multicolumn{5}{|l|}{04} \\
\hline Group I & \pm 6.39 & $1.55 \pm 2.68$ & $<0.05$ & $>0.05$ \\
\hline Group II & $78.50 \pm 4.80$ & $0.40 \pm 2.40$ & $>0.05$ & \\
\hline \multicolumn{5}{|c|}{-} \\
\hline Group I & 8.56 & $16.80+5.54$ & $<0.01$ & $<0.01$ \\
\hline Group II & $80.25 \pm 4.80$ & $2.15 \pm 3.30$ & $<0.01$ & \\
\hline \multicolumn{5}{|l|}{08} \\
\hline Group I & \pm 7.8 & $22.85 \pm 6.50$ & $<0.01$ & $<0.01$ \\
\hline Group II & $83.55 \pm 5.52$ & $5.45+5.61$ & $<0.01$ & \\
\hline \multicolumn{5}{|l|}{10} \\
\hline Group I & 6.8 & $22.70 \pm 6.11$ & $<0.01$ & $<0.01$ \\
\hline Group II & $86.20+3.67$ & $8.10 \pm 3.97$ & $<0.01$ & \\
\hline \multicolumn{5}{|l|}{12} \\
\hline Group I & \pm 5.21 & $23.15 \pm 6.35$ & $<0.01$ & $<0.01$ \\
\hline Group II & $88.25 \pm 4.25$ & $10.15 \pm 4.36$ & $<0.01$ & \\
\hline \multicolumn{5}{|l|}{14} \\
\hline Group I & \pm 5.24 & $22.95 \pm 6.83$ & $<0.01$ & $<0.01$ \\
\hline Group II & $88.30+4.86$ & $10.20+5.22$ & $<0.01$ & \\
\hline \multicolumn{5}{|l|}{20} \\
\hline Group I & \pm 4.88 & $21.95+6.50$ & $<0.01$ & $<0.01$ \\
\hline Group II & $87.40 \pm 4.21$ & $9.30 \pm 4.95$ & $<0.01$ & \\
\hline \multicolumn{5}{|l|}{25} \\
\hline Group I & 3.79 & $22.95 \pm 6.15$ & $<0.01$ & $<0.01$ \\
\hline Group II & $87.20 \pm 3.25$ & $9.10 \pm 4.39$ & $<0.01$ & \\
\hline \multicolumn{5}{|l|}{30} \\
\hline Group I & \pm 2.58 & $22.40+5.37$ & $<0.01$ & $<0.01$ \\
\hline Group II & $86.50+3.41$ & $9.10+4.39$ & $<0.01$ & \\
\hline \multicolumn{5}{|l|}{35} \\
\hline Group I & 1.75 & $21.35+6.27$ & $<0.01$ & $<0.01$ \\
\hline Group II & $86.30+3.28$ & $8.20+4.64$ & $<0.01$ & \\
\hline \multicolumn{5}{|l|}{40} \\
\hline Group I & 2.56 & $19.30+6.60$ & $<0.01$ & $<0.01$ \\
\hline Group II & $86.10+3.34$ & $8.00+4.54$ & $<0.01$ & \\
\hline \multicolumn{5}{|l|}{45} \\
\hline Group I & 2.85 & $17.45+5.89$ & $<0.01$ & $<0.01$ \\
\hline Group II & $85.85+3.50$ & $7.75+4.56$ & $<0.01$ & \\
\hline
\end{tabular}




\section{Table-V}

Changes in mean blood pressure (MBP) from preblock value and rate of changes between two groups (Mean+SD)

\begin{tabular}{|c|c|c|c|c|}
\hline $\begin{array}{l}\text { Time (min) } \\
0\end{array}$ & MBP (mmHg) & $\begin{array}{l}\text { Mean changes } \\
\text { in pressure }\end{array}$ & $\mathrm{p}$ value & Group I vs II \\
\hline Group I & 93.7 & & & \\
\hline Group II & 94.5 & & & \\
\hline Group I & \pm 5.45 & $0.35 \pm 5.45$ & $>0.05$ & $>0.05$ \\
\hline Group II & $94.25 \pm 6.40$ & $0.00+6.25$ & $>0.05$ & \\
\hline 4 & & & & \\
\hline Group I & \pm 6.72 & $20.25 \pm 0.70$ & $<0.01$ & $>0.05$ \\
\hline Group II & $73 . \overline{60} \pm 7.34$ & $21.10 \pm 6.82$ & $<0.01$ & \\
\hline Group I & \pm 6.25 & $13.20 \pm 5.25$ & $<0.01$ & $<0.05$ \\
\hline Group II & $84.90 \pm 7.10$ & $9.60 \pm 6.85$ & $<0.01$ & \\
\hline Group I & \pm 6.23 & $11.35 \pm 5.28$ & $<0.01$ & $<0.01$ \\
\hline Group II & $90 . \overline{30} \pm 5.63$ & $4.20 \pm 5.57$ & $<0.01$ & \\
\hline 10 & & & & \\
\hline Group I & \pm 4.44 & $8.05 \pm 5.25$ & $<0.01$ & $<0.01$ \\
\hline Group II & $93 . \overline{30} \pm 6.20$ & $1.10 \pm 5.75$ & $<0.05$ & \\
\hline Group I & \pm 3.6 & $7.35 \pm 4.20$ & $<0.01$ & $<0.01$ \\
\hline Group II & $95.70 \pm 4.96$ & $1.20 \pm 3.96$ & $<0.05$ & \\
\hline 14 & & & & \\
\hline Group I & \pm 5.52 & $6.55 \pm 5.50$ & $<0.01$ & $<0.01$ \\
\hline Group II & $96 . \overline{6} 0 \pm 4.96$ & $2.10 \pm 5.27$ & $<0.05$ & \\
\hline Group I & \pm 5.54 & $7.10 \pm 6.10$ & $<0.01$ & $<0.01$ \\
\hline Group II & $97 . \overline{10} \pm 5.53$ & $2.60 \pm 5.78$ & $<0.05$ & \\
\hline Group I & \pm 5.2 & $4.90 \pm 6.38$ & $<0.01$ & $<0.01$ \\
\hline Group II & $96.90 \pm 5.50$ & $2.40 \pm 5.45$ & $<0.05$ & \\
\hline 30 & & & & \\
\hline Group I & 4.85 & $4.60 \pm 4.85$ & $<0.01$ & $<0.01$ \\
\hline Group II & $97.60 \pm 4.78$ & $3.10 \pm 4.80$ & $<0.05$ & \\
\hline Group I & \pm 4.85 & $4.50 \pm 4.15$ & $<0.01$ & $<0.01$ \\
\hline Group II & $94.45 \pm 6.07$ & $1.05 \pm 6.25$ & $<0.05$ & \\
\hline Group I & \pm 4.72 & $4.85 \pm 4.81$ & $<0.01$ & $<0.01$ \\
\hline Group II & $93.35 \pm 5.45$ & $1.15 \pm 5.35$ & $<0.05$ & \\
\hline Group I & \pm 3.92 & $5.15 \pm 4.10$ & $<0.01$ & $<0.01$ \\
\hline Group II & $91 . \overline{7} 0 \pm 5.10$ & $3.20 \pm 6.25$ & $<0.05$ & \\
\hline
\end{tabular}




\section{Table-VI}

Changes in cental venous pressure (CVP) and the rate of changes between two groups (Mean $+S D)$

\begin{tabular}{|c|c|c|c|c|}
\hline Time (min) & CVP in $\mathrm{cms}$ of NS & Changes in CVP & $\mathrm{p}$ value & Group I vs II \\
\hline \multicolumn{5}{|l|}{0.0} \\
\hline Group I & $8.55 \pm 0.88$ & & & \\
\hline Group II & $8.30+0.92$ & & & \\
\hline \multicolumn{5}{|l|}{15} \\
\hline Group I & $7.50 \pm 0.68$ & $1.05 \pm 0.40$ & $<0.01$ & $<0.05$ \\
\hline Group II & $6.95 \pm 0.99$ & $1.35 \pm 0.88$ & $<0.01$ & \\
\hline \multicolumn{5}{|l|}{30} \\
\hline Group I & $7.65 \pm 0.93$ & $0.90 \pm 0.72$ & $<0.01$ & $<0.01$ \\
\hline Group II & $8.40 \pm 1.19$ & $-0.10 \pm 1.20$ & $>0.05$ & \\
\hline \multicolumn{5}{|c|}{ 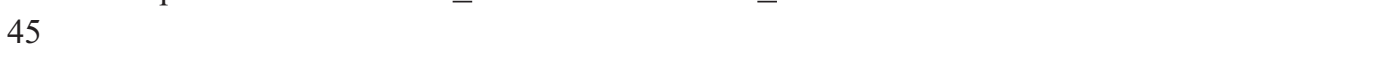 } \\
\hline Group I & $8.80 \pm 0.77$ & $-0.25 \pm 0.71$ & $>0.05$ & $>0.05$ \\
\hline Group II & $8.80 \pm 0.95$ & $-0.50 \pm 1.00$ & $<0.05$ & \\
\hline \multicolumn{5}{|l|}{60} \\
\hline Group I & $9.0 \pm 0.79$ & $-0.045 \pm 0.86$ & $<0.01$ & $>0.05$ \\
\hline Group II & $9.00 \pm 0.91$ & $-0.07 \pm 0.86$ & $<0.01$ & \\
\hline
\end{tabular}

\section{Discussion}

It is seen that metarminol is better than ephedrine at maintaining systolic arterial pressure in elderly persons. Ephedrine is used in obstetric patients as it has been found to be useful because it interferes very little with uterine blood flow ${ }^{5,6}$.Ephedrine is an alkaloid obtained from ephedra vulgaris.It resembles ephedrine except $\mathrm{OH}$ groups are missing from benzene ring and methyl group is attached to the nitrogen atom. It is abase which forms salts with various acids most common sulphate. It is colourless but gradually decomposes on exposure to light. It primarily acts indirectly but has some direct actions on $\alpha$ and beta receptors. It stimulates the heart rate and cardiac output and variably increases the peripheral resistance. As a result ephedrine usually increases the blood pressure. However, one of the disadvantages of ephedrine is its failure to correct the decreases in systemic vascular resistance. Stimulation of the alpha adrenergic receptors of smooth muscle cell in the bladder base may increase the resistance to the outflow of urine. Activation of beta adrenergic receptors in the lungs promotes bronchodilatation. It crosses the blood brain barrier and has a stimulant action on the brain. In the past ephedrine was used to treat stokes Adams attack with complete heart block and as a central nervous system stimulant in narcolepsy and the depressive states. It has been replaced by alternate modes of treatment in each of these disorders. In addition its use as a bronchodilator in patients with asthma has become less extensive with the development of beta -2 agonists. Ephedrine has been used to treat the hypotension that may occur with spinal anaesthesia. Untoward effects of ephedrine include the risk of hypertension and cardiac arrythmias, particularly after parentral administration ${ }^{7,8,9,10}$. Ephedrine is eliminated in urine largely as unchanged drug with a half life of about three to five hours. The various routes of administration of ephedrine are oral, subcutaneous, intramuscular and intravenous route.

Mephentermine has a weak alpha receptor activity but strong beta receptor activity. It rises blood pressure mainly by augmenting cardiac output. It also dilates the coronary, cerebral, splanchnic and renal blood vessels. This effect of mephentermine has an added advantage in the elderly individuals 11,12,13. Absence of bradycardia, absence of overshoot response and sustained action were other advantages of mephentermine ${ }^{14}$.

Mephentermine is a noncatecholamine sypathomimetic amine. It has 2 methyl groups on nitrogen bearing 
carbon. It is base which forms salts with various acids. It is available as a solution of mephenteramine sulphate for parental administration ${ }^{15}$. Chemically, it resembles sympathomimatic amines such as amphetamine and desoxyephedrine. It has got a sypathomimetic action. It has a combination of ionotropic and vasoconstrictor actions. Mephentermine has a weak alpha receptor activity but strong beta receptor activity. It increases the blood pressure by augmenting the cardiac output. It has a dilating effect on the coronary, cerebral, splanchnic and renal blood vessels. Adverse effects are related to central nervous system stimulation, hypertension and arrythmias. The change in heart rate is variable depending on the degree of vagal tone. It is used to prevent hypotension which accompanies spinal anaesthesia 16,17 .

Studies on elderly individuals have shown that they have depleted catecholamine stores and ephedrine which acts mainly by release of noradrenaline could not be a better choice than mephentermine. so, we conducted a comparative study between these two vasopressors to decide which would be more effective, in treating hypotension after subarachnoid block in elderly individuals.

\section{Heart Rate:}

Patients in both the groups showed a statistically significant rise in heart rate from $4^{\text {th }}$ minute $(p<0.05)$ and $6^{\text {th }}$ minute $(\mathrm{p}<0.01)$ respectively and this rise persisted upto 45 minutes $(p<0.01)$. the rise in heart rate was significantly greater in group I as compared to group II at all time intervals.

Mephentermine has been found to cause reflex slowing of heart rate when used in larger doses of 10 to $20 \mathrm{mg}$. in our study, mephentermine group showed a rise in heart rate using a bolus of $10 \mathrm{mg}$ followed by an infusion of $1 \mathrm{mg} / \mathrm{min}$. the probable reason for increased heart rate by mephentermine in our study may be related to the rise of bolus dose followed by infusion since vagal slowing has been seen only with bolus doses.

Also the bolus dose of mephentermine used in our study was on the lower side. Slowing of heart rate has not been documented by mephentermine in our study because the bolus dose of mephentermine was on the lower side.

\section{Blood Pressure :}

There was significant fall in blood pressure from baseline in both the groups. In our study, the delay the delay in fall in blood pressure in fluid group is related to the initial rise in CVP which is sufficient to counteract the venodilatation resulting from subarachnoid block. In the metarminol group systolic blood pressure was maintained in all patients and it was greater than fluid group 15 minutes after induction. The systolic arterial pressure returned to baseline by 15 minutes.

\section{Central Venous Pressure (CVP) :}

In both groups I \& II, the CVP dropped from baseline value 15 mins after subarachnoid block. After 30 mins, the CVP was comparable to the baseline in group II whereas it was still low in group I. beyond 30 mins the CVP was comparable to the baseline in both the groups. The low CVP in group I upto 30 mins may explain the inability of ephedrine to maintain $\mathrm{BP}$ comparable to baseline.

\section{Conclusions}

The following conclusions were drawn from the present study.

1. There was a statistically significant rise in heart rate from the baseline at $4^{\text {th }}$ minute in Group I and at $6^{\text {th }}$ minute inGroup II which persisted upto the $45^{\text {th }}$ minute of the study but the rise in heart rate in Group I was significantly grater than Group II at all time intervals.

2. There was arise in systolic blood pressure in both Group I and Group II after the start of vasopressors but the rise in systolic blood pressure was more in Group II as compared to Group I. similarly, it was observed that diastolic blood pressure and mean blood pressure was better controlled in Group II (Mephentermine group) and the blood pressure came close to the baseline earlier in Group II as compared to Group I.

3. The drop in CVP was significantly more in group II than group I but it came closer to baseline earlier in group II patients as compared to the patients of group I. Therefore, in conclusion, though both ephedrine and mephentermine are effective in treatment of spinal hypertension of elderly patients, but, mephentermine gives better haemodynamics and stability than ephedrine. 


\section{References}

1. Greene N.M. Physiology of Spinal anaesthesia. Fourth edition. Baltimore : Williams \& Wilkins, 1981 : VII -IX, 134-200.

2. Bruch CJ, Harrison RT. The effect of spinal anaesthesia on the cardiac output. Arch. Surg $1950 ; 21: 330-32$.

3. Smith HW, Rovenstine EA, Goldring, Chasis H, Ranges HA. The effect of spinal anaesthesia on the circulation in normal, unoperated man with reference to the autonomy of the arterioles and especially those of the renal circulation. J.clin.invest $1959: 18: 319-339$.

4. Critchley LAH. Hypotension subarachnoid block and the elderly. Br J anaesth 1996; 1139-43.

5. Kang VG, Caritis S. Prophylactic intravenous ephedrine infusion during spinal anaesthesia for caesarean section.Anaesth Analg 1982; 61 : 839-42.

6. Critchley LAH, Stuart J, Conway F. Hypotension during subarachnoid anaesthesia: Haemodynamic effects of ephedrine. Br.J.Anaesth 1995,74 : 373-8.

7. Carpenter RL, Caplan RA, Brown DL, Slephenson RN, WuR. Incidence and risk factors for side effects of spinal anaesthesia.Anaesthesiology $1992 ; 76$ : 906-916.

8. Owen H, Cousins MJ. Subarachnoid and extradural anaesthesia. Anaesthesia, second volume, edited by Walter S. Nimino and Graham Smith. $1990 ; 2$ : 1034-70.

9. Reynolds RJM Spinal and Epidural block. A practice of anaesthesia, 5th edition ed by Wylie and Churchill
Davidson. HE PG publishing Pvt Ltd., New Delhi 1984, 856-92.

10. Echenhoff JE, Hafkenshiel JH, Fultz. Influence of hypotension on coronary blood flow, cardiac work and cardiac efficacy. AMJ Physiol $1984 ; 152$ : 545-553.

11. McCrae AF Wild Smith J. Prevention and treatment of hypotension during central neural block. Br. J. Anaesth 1993, 70: 672-80.

12. Malmquist LA, Bengisson M. Sympathetic activity and Haemodynamic variables during spinal analgesia in man. Acta Anaesth Scand $1987 ; 31: 467-73$.

13. Coe AJ. Is crystalloid preloading useful in spinal anaesthesia in elderly? Anaesthesia 1990 ; 45 : 241-3.

14. Buggy D, Higgins P. Prevention of spinal anaesthesia induced hypotension in the elderly. Comparison between preanaesthetic administration of cyrstalloids, colloids and noprehydration. Anaesth Analg 1997 ; 84 : 106-10.

15. Critchley LAH, Short T, Gin T. Hypotension during subarachnoid anaesthesia. Haemodynamic analysis of three treatments. Br J. Anaesth $1994 ; 72$. 151 -5.

16. Critchley LAH, Conway F. Hypotension during subarachnoid anaesthesia. Effects of colloids and metarminol. Br J. Anaesth 1996; 76 . 734 -6.

17. Myres CR, Mathews TP, Jenicek JA. Clinical response to selected vasopressors during spinal anaesthesia. A. M. Pract, Dig. Treat, 1961; $12: 828$. 